\title{
Intermolecular Aryne Ene Reaction of Hantzsch Esters: Stable Co- valent Ene Adducts from a 1,4-Dihydropyridine Reaction
}

\author{
Piera Trinchera, Weitao Sun, Jane E. Smith, David Palomas, Rachel Crespo-Otero and Christopher R. \\ Jones*
}

School of Biological and Chemical Sciences, Queen Mary University of London, Mile End Road, London E1 4NS, UK.

Supporting Information Placeholder

\begin{abstract}
The reaction of arynes with 1,4dihydropyridines affords 2-aryl-1,2-dihydropyridines or 2-methylene-3-aryl-1,2,3,4-tetrahydropyridines via a regioselective $\mathrm{C}-2$ or $\mathrm{C}-3$ arylation. These compounds are the first series of isolable and bench-stable covalent ene adducts formed between dihydropyridines and unsaturated substrates. Experimental studies and DFT calculations provide mechanistic support for a concerted intermolecular aryne ene process, which may have implications for $\mathrm{NAD}(\mathrm{P}) \mathrm{H}$ model reactions.
\end{abstract}

1,4-Dihydropyridines (1,4-DHPs) have been widely exploited as reducing agents in synthesis ${ }^{1}$ and comprise the core of the biological redox cofactors, $\mathrm{NAD}(\mathrm{P}) \mathrm{H}$. As a result, the precise nature of the overall hydride transfer (HT) between 1,4-DHPs (PH) and substrates (Y) has been the subject of numerous mechanistic investigations (Scheme 1a). ${ }^{2}$ One-step ionic HT has prevailed, ${ }^{3}$ in part due to a lack of experimental evidence for intermediates that would arise from alternative single electron transfer ${ }^{4}$ or pericyclic ene pathways. ${ }^{5}$ However, a recent seminal study by Erb involving NADPH-dependent enzymes, ${ }^{6}$ as well as reports from Iqbal ${ }^{7 \mathrm{a}}$ and Libby ${ }^{7 \mathrm{~b}}$ using NADH model DHPs, support the fundamental possibility of an ene mechanism for HT. Using in situ spectroscopy, unstable covalent ene adducts P.YH were successfully characterized prior to their decomposition to ionic species $\mathbf{Y H}^{-}$and $\mathbf{P}^{+}$, then eventual product $\mathbf{Y H}_{2}$. It follows that the relative stability of adduct P.YH is key to the outcome of DHP-driven reductions. Therefore we reasoned that careful selection of substrate $\mathbf{Y}$ could reverse the established equilibrium between $\mathbf{P . Y H}$ and $\mathbf{Y} \mathbf{H}^{-} / \mathbf{P}^{+}$, revealing a new approach to functionalized DHPs, as well as providing bench-stable DHP-ene adducts for the first time; a significant development towards the full comprehension of 1,4-DHP-mediated reductions.

We envisioned that the use of arynes $(\mathbf{Z})$ as substrates for 1,4-DHP reactions should result in the formation of

\section{Scheme 1. 1,4-Dihydropyridine reaction pathways}
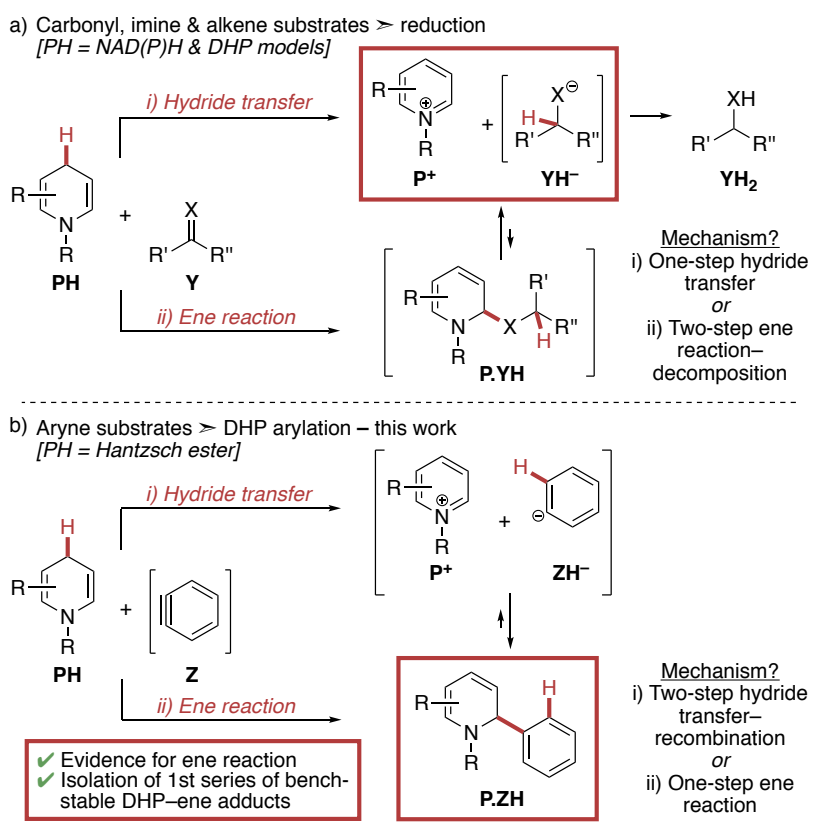

stable 2-aryl-1,2-DHP adducts P.ZH, as decomposition would be disfavoured due to the instability of aryl anion $\mathbf{Z H}^{-}$(Scheme 1b). Arynes are particularly versatile reactive intermediates that have enjoyed a remarkable renaissance in recent years. ${ }^{8}$ This can be attributed to the development of mild and convenient methods to access arynes, such as 2-(trimethylsilyl)aryl triflates ${ }^{9}$ and the hexadehydro-Diels-Alder reaction of polyalkynes, ${ }^{10}$ which have led to the discovery of exciting new aryne reactivity motifs. ${ }^{8}$ Utilizing 1,4-DHPs and reactive aryne intermediates, herein we describe the synthesis of the first series of bench-stable covalent ene adducts from a DHP reaction with an unsaturated substrate. Whilst removed from a true biological model, the stable ene adducts obtained offered a unique opportunity to study the competing HT and pericyclic mechanisms identified in previous NADH model reactions. To this end, experimental and computational evidence is presented that 
supports a concerted ene reaction. From a synthetic perspective, direct arylation of readily available 1,4-DHPs represents a new method to prepare 1,2-DHPs bearing a challenging all-carbon quaternary stereogenic centre. ${ }^{1,12}$

Hantzsch esters (HEs) are readily accessible 1,4-DHPs that have been widely exploited in synthesis ${ }^{1}$ and as pharmaceutical targets. ${ }^{13}$ As a result, we selected HEs as the DHP component in our investigations, ${ }^{14}$ which began with HE $1 \mathbf{a}(\mathrm{R}=\mathrm{Ph})$ and $o$-silylaryl triflate $\mathbf{2 a}\left(\mathrm{R}^{1}=\mathrm{H}\right)$ (Scheme 2). Following a survey of solvents and fluoride sources we were pleased to observe that cesium fluoride in acetonitrile at $70{ }^{\circ} \mathrm{C}$ led to the complete consumption of $1 \mathbf{a}$ and formation of the desired covalent ene adduct 3aa, which was bench-stable and isolated in $75 \%$ yield.

\section{Scheme 2. C-2 Arylation of HE derivatives ${ }^{a}$}

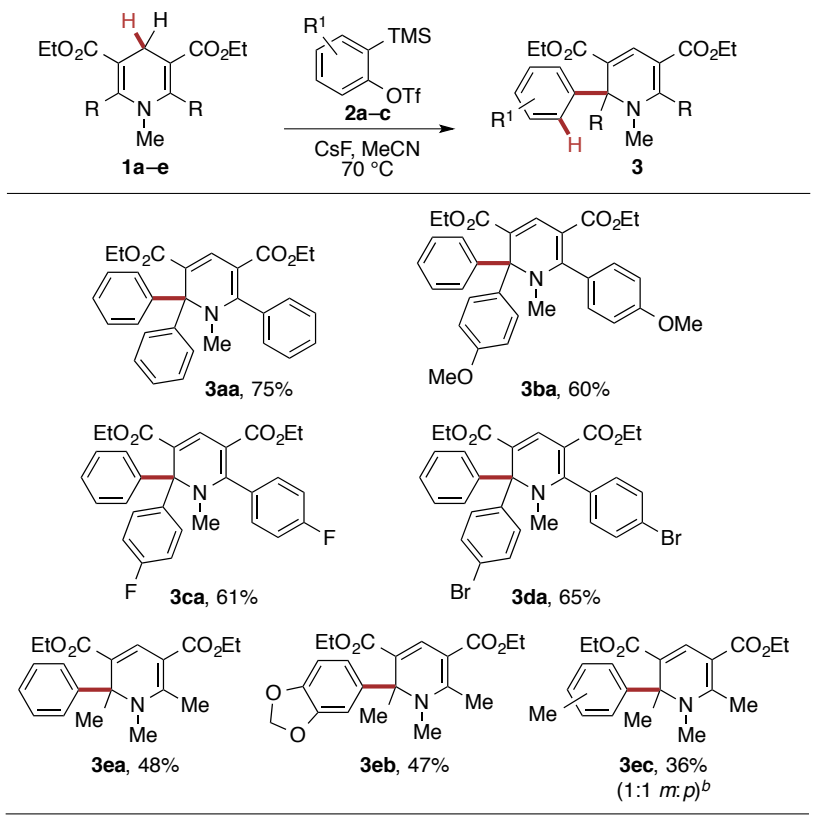

${ }^{a}$ Reaction conditions: HE 1 (1.0 equiv), 2 (2.5 equiv), $\mathrm{CsF}$ (6.0 equiv) in acetonitrile $(0.1 \mathrm{M}), 70{ }^{\circ} \mathrm{C}$ for 15 hours. Yields of isolated products throughout. ${ }^{b}$ Ratio determined by analysis of the ${ }^{1} \mathrm{HNMR}$ spectrum.

The reaction was equally viable with electron-rich ( $p$ $\mathrm{OMe}, \mathbf{1 b})$ and electron-poor ( $p-\mathrm{F}, \mathbf{1 c}$ and $p-\mathrm{Br}, 1 \mathbf{1 d}) 2,6-$ diaryl $\mathrm{HE}$ derivatives, generating the quaternary $\mathrm{C}-2$ arylated 1,2-DHPs 3ba-da in good yields (60-65\%). Incorporation of halogen atoms in $\mathbf{3 c a}$ and $\mathbf{3 d a}$ is particularly noteworthy, as these groups can be problematic in organometallic-based approaches to heterocycle arylation. Next we turned our attention to HE derivative 1e $(\mathrm{R}=\mathrm{Me})$ and again observed exclusive formation of the desired ene adduct 3ea. Treatment of 1e with methylenedioxy aryne precursor $\mathbf{2 b}$ produced the corresponding 2-aryl-1,2-DHP 3eb in 47\% yield, whilst unsymmetrical 4-methylbenzyne precursor $2 \mathbf{c}$ provided $3 \mathbf{e c}$ as a 1:1 mixture of meta and para regioisomers.

We continued our investigations into the scope of the DHP-aryne reaction by introducing alkyl and aryl sub- stituents to the C-4 position of the HEs (1f $-\mathbf{i})$. Surprisingly, none of the expected $\mathrm{C}-2$ ene adduct was observed when 2,6-dimethyl-4-phenyl HE 1 f was subjected to the standard arylation conditions; instead an alternative bench-stable covalent ene adduct was isolated in $52 \%$ yield, the highly substituted 2-methylene-3-aryl-1,2,3,4tetrahydropyridine (THP) 4fa (Scheme 3). Similarly,

\section{Scheme 3. C-3 Arylation of C-4 HE derivatives ${ }^{a}$}

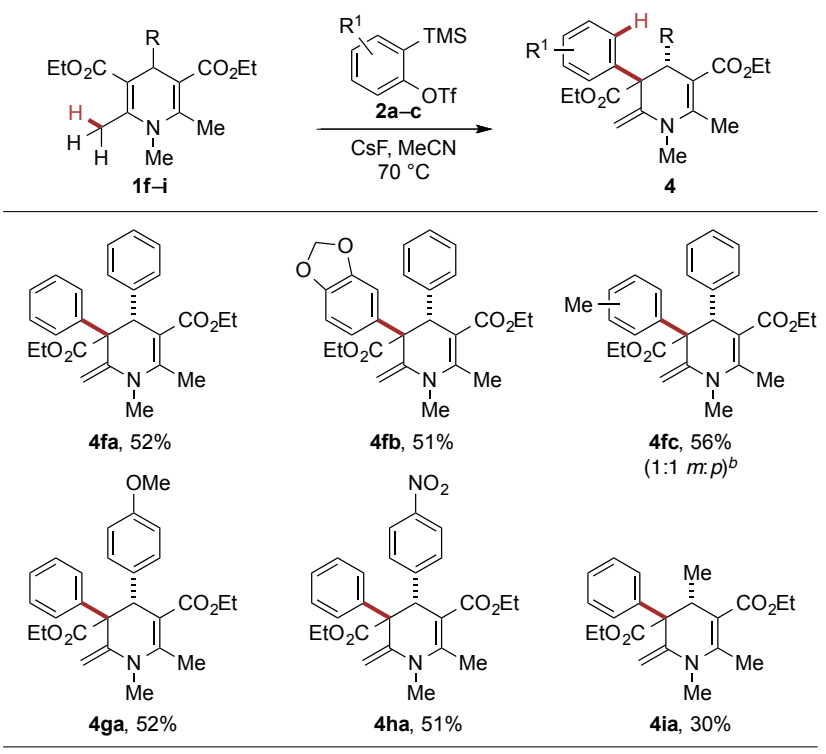

${ }^{a}$ Reaction conditions are as shown in Scheme 2. Yields of isolated products throughout. ${ }^{b}$ Ratio determined by analysis of the ${ }^{1} \mathrm{HNMR}$ spectrum.

exposure of $\mathbf{1 f}$ to substituted aryne precursors $\mathbf{2 b}$ and $\mathbf{2 c}$ resulted in the corresponding quaternary C-3 arylated THPs $\mathbf{4 f b}$ and $\mathbf{4 f c}$ (generated as a 1:1 mixture of meta and para regioisomers). The reaction with benzyne precursor 2a was equally effective for substrates with electron-rich $(p-\mathrm{OMe}, \mathbf{1 g})$ and electron-poor $\left(p-\mathrm{NO}_{2}, \mathbf{1 h}\right) \mathrm{C}$ 4 aryl substituents, affording THPs 4 ga and 4 ha respectively. Aliphatic C-4 substitution of the HE (Me, 1i) was also tolerated, affording C-3 arylated adduct 4ia in lower yield $(30 \%)$ but still no trace of the C-2 product. ${ }^{15}$ Interestingly, the C-3 arylation of all 1,4-DHP derivatives $\mathbf{1 f}-$ i afforded a single product diastereoisomer. NOESY experiments conducted on THP 4ia indicated an anti relationship between the $\mathrm{C}-3$ phenyl group and the $\mathrm{C}-4$ methyl substituent; ${ }^{16}$ consistent with the aryne approaching from the opposite face of the HE to the C-4 substituent. There are very few reports describing the synthesis of highly functionalized 2-methylene-1,2,3,4-THPs ${ }^{17}$ and adducts $\mathbf{4 f}-\mathbf{i}$ are the first examples to contain aryl groups at an all-carbon C-3 quaternary centre.

With a selective synthesis of stable and isolable C-2 and $\mathrm{C}-3$ covalent ene adducts in hand, we sought to gain an insight into the mechanisms in operation. There are two main pathways by which the C-2 arylation of HEs is likely to occur: two-step hydride transfer-recombination (via either radical or ionic intermediates), or a concerted 
Scheme 4. Mechanistic studies ${ }^{a}$

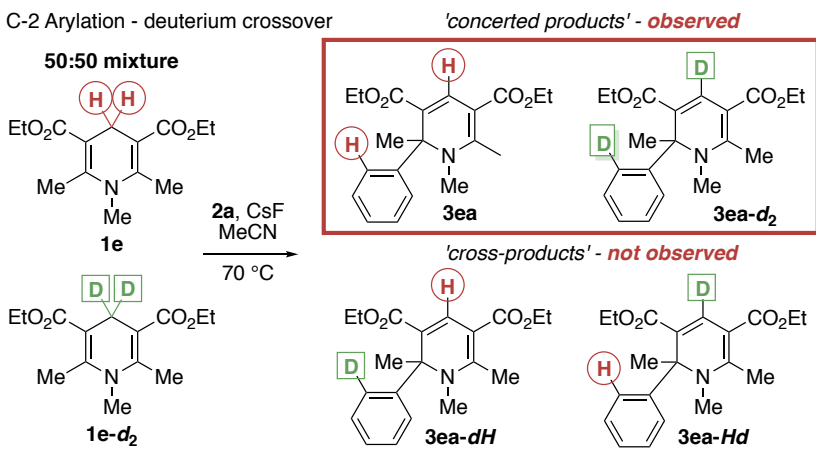

${ }^{a}$ Reaction conditions are as shown in Scheme 2.

aryne ene reaction (see Scheme 1b). To this end, an equimolar mixture of 2,6-dimethyl $\mathrm{HE}$ 1e and bisdeuterated analogue, 2,6-dimethyl-4,4- $d_{2}$ HE $\mathbf{1 e}-\boldsymbol{d}_{2}$, was treated with benzyne precursor 2a (Scheme 4a). Analysis of the reaction mixture revealed only 'concerted products' 3ea and 3ea- $\boldsymbol{d}_{2} \cdot{ }^{18}$ Whilst this is not definitive proof of a concerted process, the absence of mono-deuterated

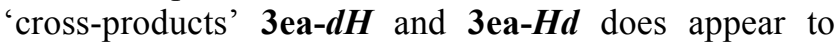
support this hypothesis, as the formation of ionic intermediates $\mathbf{P}^{+}$and $\mathbf{Z} \mathbf{H}^{-}$from hydride transfer (see Scheme 1b) would be expected to result in at least trace amounts of crossover. Similarly, adducts from potential 1,4addition to $\mathbf{P}^{+}$have never been detected. With a view to providing more mechanistic detail, we performed DFT calculations (B3LYP-D3/def2-TZVP in acetonitrile) ${ }^{19}$ on HE 1e. A low activation barrier to the concerted reaction $(7.5 \mathrm{kcal} / \mathrm{mol})$ was found, whereas no transition structure (TS) for either stepwise process (radical or ionic) could be located; suggesting that the arylation proceeds via a concerted reaction and is in agreement with the experimental evidence. Arynes are well-established enophiles and a number of intramolecular aryne alkeneene reactions have been developed, ${ }^{10,20}$ as well as intermolecular hetera-ene ${ }^{21}$ and propargylic-ene reactions. ${ }^{22}$ Intermolecular aryne alkene-ene processes analogous to our hypothesis have been reported, however they are typically limited to simpler substrates. ${ }^{23,24}$

Similar mechanistic considerations surrounded the formation of the C-3 adducts $\mathbf{4 f}-\mathbf{i}$, as they could arise from either an alternative aryne ene reaction (involving $\mathrm{C}-3$ and a C-H from the exocyclic methyl group of 1f-i) or via stepwise addition of aryne at C-3, followed by $\alpha$ deprotonation of an intermediate iminium ion. Again, experimental evidence tentatively favoured an ene process, as arylation of HE $\mathbf{1 f}$ in acetonitrile- $d_{3}$ afforded $\mathbf{4 f a}$ with no trace of any deuterium incorporation that would be expected from an intermediate zwitterion deprotonating acetonitrile. ${ }^{25}$ To further probe the mechanism, DFT calculations (B3LYP-D3/def2-TZVP in acetonitrile) ${ }^{19}$ were conducted using HE 1f. Once more these provided support for a concerted reaction $\left(\Delta \mathrm{G}^{\ddagger}=9.7 \mathrm{kcal} / \mathrm{mol}\right)$ and again no TS for a stepwise process was found.
Scheme 5. C-2 Arylation of C-4 HE derivatives ${ }^{a}$

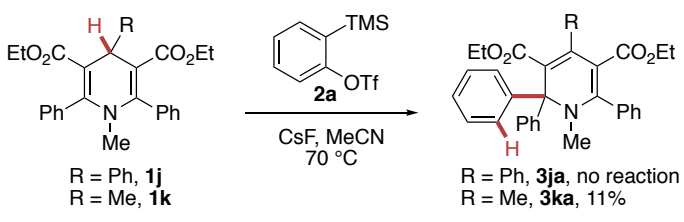

${ }^{a}$ Reaction conditions are as shown in Scheme 2.

Finally we turned our attention to understanding the origin of the divergent $\mathrm{C}-2 / \mathrm{C}-3$ arylation. Using C-4 substituted HEs incapable of forming the exocyclic alkene within THPs 4, no reaction occurred with 2,4,6triphenyl HE 1j, however the less hindered C-4 methyl analogue $1 \mathbf{k}$ did afford a small amount of $\mathrm{C}-2$ ene adduct 3ka (11\%) (Scheme 5). This suggests that bulkier $\mathrm{C}-4$ groups lead to greater suppression of $\mathrm{C}-2$ arylation. Additional DFT calculations (B3LYP-D3/def2-TZVP in acetonitrile) ${ }^{19}$ were performed on 2,6-dimethyl-4-phenyl HE $1 f$ to compare the theoretical reaction energy profiles for C-2 and C-3 arylation (Figure 1a). Firstly, the large exothermic character and low activation energies of both processes are consistent with the proposed involvement of the aryne 1,2-pseudodiradical vinyl resonance structure in ene reactions. ${ }^{26}$ Secondly, a lower activation barrier for the formation of C-3 adduct $\mathbf{4 f a}(9.7 \mathrm{kcal} / \mathrm{mol})$ was found in comparison to $\mathrm{C}-2$ adduct 3 fa (11.9 $\mathrm{kcal} / \mathrm{mol}$ ); in agreement with the experimental observations. Analysis of the two TSs (TS-3fa and TS-4fa) reveals that the $\mathrm{C}-4$ substituent causes the adjacent ethyl ester groups to project onto the opposite face of the 1,4DHP ring and thus hinder the aryne approach (Figure 1b). This affects $\mathrm{C}-2$ arylation more significantly than $\mathrm{C}-3$, as evidenced by the increased $\mathrm{C}_{\text {aryne }}-\mathrm{C}_{\mathrm{DHP}}$ bond

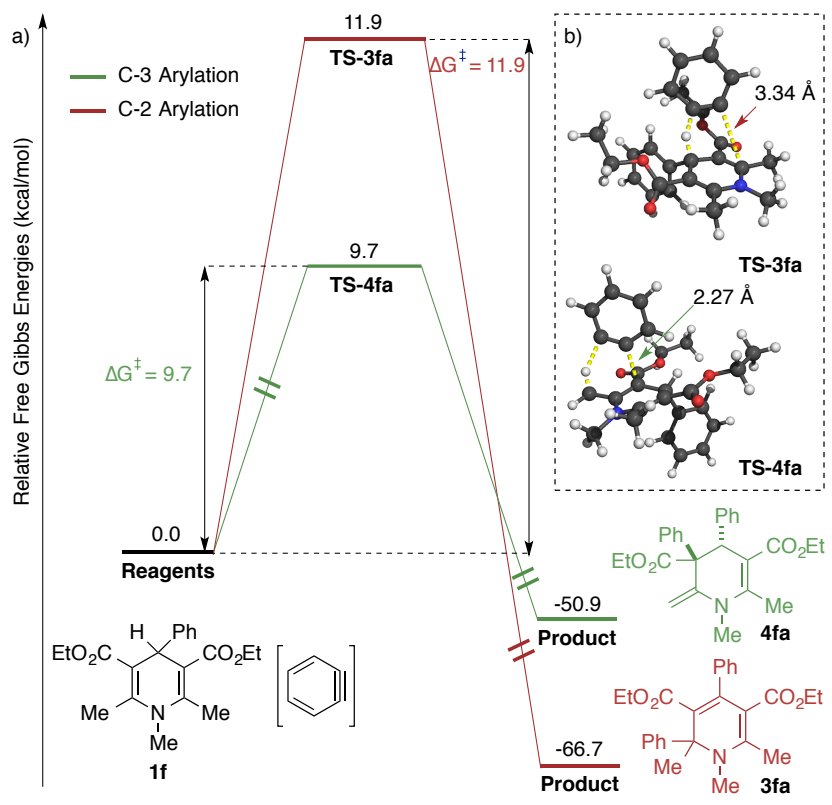

Figure 1. a) Calculated C-2 and C-3 arylation reaction profiles of HE 1f at B3LYP-D3/def-TZVP level of theory. b) Computed transition structures TS-3fa and TS-4fa. 
length in TS-3fa (3.34 $\AA$ ) compared to TS-4fa (2.27 $\AA$ ), resulting in a more asynchronous distribution of charge and a higher energy TS.

In summary, we have prepared a range of covalent ene adducts formed between 1,4-DHPs and unsaturated substrates; the first bench-stable examples of model intermediates from the ene mechanism for $\mathrm{NAD}(\mathrm{P}) \mathrm{H}$ redox reactions first proposed by Hamilton. ${ }^{5}$ DFT calculations and experimental analyses provide support for the generation of the adducts by an intermolecular aryne ene mechanism. Control of the arylation reaction course is achieved through the substitution pattern around the HEs, rendering this a flexible approach to highly functionalised 2-aryl-1,2-DHP or 3-aryl-1,2,3,4-THP derivatives bearing all-carbon quaternary stereogenic centres.

\section{ASSOCIATED CONTENT}

The Supporting Information is available free of charge on the ACS Publications website.

Experimental details for the preparation of new compounds; spectroscopic data for their characterization, including copies of ${ }^{1} \mathrm{H}$ and ${ }^{13} \mathrm{C}$ NMR spectra; LC-MS and GC-MS data for deuterium competition experiments (PDF).

\section{AUTHOR INFORMATION}

\section{Corresponding Author}

*c.jones@qmul.ac.uk

\section{Notes}

The authors declare no competing financial interest.

\section{ACKNOWLEDGMENT}

We are grateful to the EPSRC (EP/M026221/1, C.R.J. \& P.T. \& EP/K000128/1, R.C.-O.), Ramsay Memorial Trust (C.R.J.), China Scholarship Council (W.S.) and the RSC Research Fund for financial support. We thank the EPSRC UK National Mass Spectrometry Facility at Swansea University. Nada Kurdi, Gregory Craven and Gregory Coates (QMUL) are thanked for early experimental assistance.

\section{REFERENCES}

(1) Selected reviews: (a) Ouellet, S. G.; Walji, A. M.; Macmillan, D. W. C. Acc. Chem. Res. 2007, 40, 1327. (b) Zheng, C.; You, S.-L. Chem. Soc. Rev. 2012, 41, 2498. (c) Wang, D.; Astruc, D. Chem. Rev. $\mathbf{2 0 1 5}, 115,6621$.

(2) (a) Westheimer, F.; Fisher, H. F.; Conn, E. E.; Vennesland, B. J. Am. Chem. Soc. 1951, 73, 2403. (b) Maclnnes, I.; Nonhebel, D. C.; Orszulik, S. T.; Suckling, C. J. J. Chem. Soc., Perkin Trans. 1 1983, 2777. (c) Yasui, S.; Ohno, A. Bioorg. Chem. 1986, 14, 70. (d) Cheng, J.-P.; Lu, Y.; Zhu, X; Mu, L. J. Org. Chem. 1998, 63, 6108. (e) Yasui, S.; Okamura, M.; Fujii, M. Rev. Heteroatom Chem. 1999, 20, 145.

(3) (a) Abeles, R. H.; Hutton, R. F.; Westheimer, F. J. Am. Chem. Soc. 1957, 79, 712. (b) Wu, Y. D.; Houk, K. J. Am. Chem. Soc. 1987, $109,2226$.

(4) (a) Inagaki, S.; Hirabayashi, Y. Bull. Chem. Soc. Jpn. 1977, 50, 3360. (b) Gebicki, J.; Marcinek, A.; Zielonka, J. Acc. Chem. Res. 2004, 37, 379 .

(5) Hamilton, G. Prog. Bioorg. Chem. 1971, 1, 83.
(6) Rosenthal, R. G.; Ebert, M. O.; Kiefer, P.; Peter, D. M. Vorholt, J. A.; Erb, T. J. Nat. Chem. Biol. 2014, 10, 50.

(7) (a) Sulzbach, R. A.; Iqbal, A. F. M. Angew. Chem. Int. Ed. 1971, 10, 733. (b) Libby, R. D.; Mehl, R. A. Bioorg. Chem. 2012, 40, 57.

(8) Recent reviews: (a) Bhunia, A.; Yetra, S. R.; Biju, A. T. Chem. Soc. Rev. 2012, 41, 3140. (b) Tadross, P. M.; Stoltz, B. M. Chem. Rev. 2012, 112, 3550. (c) Hoffmann, R. W.; Suzuki, K. Angew. Chem. Int. Ed. 2013, 52, 2655. (d) Holden, C.; Greaney, M. F. Angew. Chem. Int. Ed. 2014, 53, 5746. (e) Yoshida, S.; Hosoya, T. Chem. Lett. 2015 $44,1450$.

(9) Himeshima, Y.; Sonoda, T.; Kobayashi, H. Chem. Lett. 1983, 12,1211 .

(10) (a) Hoye, T. R.; Baire, B.; Niu, D.; Willoughby, P. H.; Woods, B. P. Nature 2012, 490, 208. (b) Niu, D.; Willoughby, P. H.; Woods, B. P.; Baire, B.; Hoye, T. R. Nature 2013, 501, 531. (c) Karmakar, R.; Lee, D. Chem. Soc. Rev. 2016, 45, 4459. (d) Xu, F.; Xiao, X.; Hoye, T. R. J. Am. Chem. Soc. 2017, 139, 8400.

(11) Review of 1,2-DHPs: Silva, E. M. P.; Varandas, P. A. M. M.; Silva, A. M. S. Synthesis 2013, 45, 3053.

(12) Selected examples using (a) pre-prepared building blocks: Tejedor, D.; Cotos, L.; Méndez-Abt, G.; García-Tellado, F. J. Org. Chem. 2014, 79, 10655. (b) 1,2-DHP functionalization: Zou, G.-F.; Zhang, S.-Q.; Wang, J.-X.; Liao, W.-W. J. Org. Chem. 2016, 81, 5717. (c) Reductive alkylation of pyridines: Donohoe, T. J.; McRiner, A. J.; Sheldrake, P. Org. Lett. 2000, 2, 3861.

(13) Edraki, N.; Mehdipour, A. R.; Khoshneviszadeh, M.; Miri, R. Drug Discov. Today 2009, 14, 1058.

(14) See Supporting Information for the preparation of HEs. $\mathrm{N}$ methylation prevented deleterious aryne insertion into the N-H bond.

(15) Unreacted starting material was also recovered from the C-3 arylation of HEs $\mathbf{1} \mathbf{f}-\mathbf{i}$.

(16) See Supporting Information for more details.

(17) (a) Aritomi, J.; Nishimura, H. Chem. Pharm. Bull. 1981, 29, 1193. (b) Hartman, G. D.; Phillips, B. T.; Halczenko, W. J. Org. Chem. 1985, 50, 2423. (c) Hartman, G. D.; Halczenko, W.; Cochran, D. W. Can. J. Chem. 1986, 64, 556. (d) Patterson, J. W. J. Heterocycl. Chem. 1986, 23, 1689. (e) Rimoli, M. G.; Avallone, L.; Zanarone, S.; Abignente, E.; Mangoni, A. J. Heterocycl. Chem. 2002, 39, 1117.

(18) See Supporting Information for full details of isotope studies.

(19) See Supporting Information for full details; calculations were performed using Queen Mary MidPlus computational facilities supported by QMUL Research-IT.

(20) (a) Candito, D. A.; Panteleev, J.; Lautens, M. J. Am. Chem. Soc. 2011, 133, 14200. (b) Karmakar, R.; Mamidipalli, P.; Yun, S. Y.; Lee, D. Org. Lett. 2013, 15, 1938. (c) Niu, D.; Hoye, T. R. Nat. Chem. 2014, 6, 34

(21) (a) Aly, A. A.; Mohamed, N. K.; Hassan, A. A.; Mourad, A.F. E. Tetrahedron 1999, 55, 1111. (b) Aly, A. A.; Shaker, R. M. Tetrahedron Lett. 2005, 46, 2679. (c) Pirali, T.; Zhang, F.; Miller, A. H.; Head, J. L.; McAusland, D.; Greaney, M. F. Angew. Chem. Int. Ed. 2012, 51, 1006.

(22) Jayanth, T. T.; Jeganmohan, M.; Cheng, M.-J.; Chu, S.-Y.; Cheng, C.-H. J. Am. Chem. Soc. 2006, 128, 2232.

(23) Hydrocarbons with few heteroatoms: (a) Arnett, E. M. J. Org. Chem. 1960, 25, 324. (b) Simmons, H. E. J. Am. Chem. Soc. 1961, 83, 1657. (c) Friedman, L.; Osiewicz, R. J.; Rabideau, P. W. Tetrahedron Lett. 1968, 9, 5735. (d) Wasserman, H. H.; Solodar, A. J.; Keller, L. S. Tetrahedron Lett. 1968, 9, 5597. (e) Crews, P.; Beard, J. J. Org. Chem. 1973, 38, 522. (f) Garsky, V.; Koster, D. F.; Arnold, R. T. J. Am. Chem. Soc. 1974, 96, 4207. (g) Wasserman, H. H.; Keller, L. S. Tetrahedron Lett. 1974, 15, 4355. (h) Nakayama, J.; Yoshimura, K. Tetrahedron Lett. 1994, 35, 2709. (i) Chen, Z.; Liang, J.; Yin, J.; Yu, G.-A.; Liu, S. H. Tetrahedron Lett. 2013, 54, 5785. (j) Bhojgude, S. S.; Bhunia, A.; Gonnade, R. G.; Biju, A. T. Org. Lett. 2014, 16, 676.

(24) Example with imidazole derivative: Watson, L. J.; Harrington, R. W.; Clegg, W.; Hall, M. J. Org. Biomol. Chem. 2012, 10, 6649.

(25) Stephens, D.; Zhang, Y.; Cormier, M.; Chavez, G.; Arman, H.; Larionov, O. V. Chem. Commun. 2013, 49, 6558.

(26) Perez, P.; Domingo, L. R. Eur. J. Org. Chem. 2015, 2826. 